\title{
A crise de legitimidade da governança climática global. Combinação de uma perspetiva marxista e polanyiana
}

The Legitimacy Crisis of Global Climate Governance. Combining a Marxist and Polanyian Perspective

La crise de légitimité de la gouvernance climatique globale. Association d'une perspective marxiste et polanyienne

Jonas Van Vossole

\section{OpenEdition}

\section{Journals}

Edição electrónica

URL: http://journals.openedition.org/rccs/5275

DOI: $10.4000 /$ rccs. 5275

ISSN: 2182-7435

\section{Editora}

Centro de Estudos Sociais da Universidade de Coimbra

Edição impressa

Data de publição: 1 Maio 2013

Paginação: 153-176

ISSN: 0254-1106

Refêrencia eletrónica

Jonas Van Vossole, «A crise de legitimidade da governança climática global. Combinação de uma perspetiva marxista e polanyiana », Revista Crítica de Ciências Sociais [Online], 100 | 2013, colocado online no dia 28 outubro 2013, criado a 21 abril 2019. URL : http://journals.openedition.org/rccs/5275 ; DOI : $10.4000 /$ rccs. 5275 


\title{
A crise de legitimidade da governança climática global. Combinação de uma perspetiva marxista e polanyiana
}

\begin{abstract}
Este artigo enquadra os atuais problemas da Rio+20, o falhanço da Cimeira de Copenhaga (COP15) e, mais recentemente, dos mercados de carvão numa ampla crise de legitimidade da governança global, consequência da crise global da socioecologia capitalista. Dois mecanismos dão origem a esta perda de legitimidade, o desenvolvimento desigual e a mercantilização; ou seja a reconfiguração das relações de força entre atores e a destruição dos laços sociais. Como resultado, tanto vencedores como perdedores contestam a legitimidade das instituições que governam a reprodução do capitalismo global. Neste artigo distinguimos respetivamente a contestação tipo-Marx de novas/os classes/Estados emergentes e tipo-Polanyi das vítimas da mercantilização global. Na esfera da governança climática, estes vencedores e perdedores são representados pelos BRICS nas negociações climáticas e pelo movimento global de justiça ambiental.
\end{abstract}

Palavras-chave: capitalismo; governança; justiça ambiental; legitimidade; Rio+20.

\section{Introdução}

Após o fracasso da cimeira Rio $+20^{1}$ da ONU em junho de 2012, parece não haver melhores perspetivas para as negociações da COP $19^{2} \mathrm{em}$ Varsóvia (Leahy, 2013); a governança climática global mantém-se numa crise crónica. A incapacidade dos dirigentes políticos para encontrarem uma solução credível para os problemas da mudança climática, num momento em que os efeitos socioecológicos destas mudanças se tornam assustadoramente reais para a humanidade, traz de volta o debate relativamente recente entre autores como Bodansky (1999), Bernstein (2004)

\footnotetext{
* Este ensaio foi apresentado no seminário de doutoramento "A reflexão crítica num mundo plural", coordenado pela Doutora Stefania Barca.

${ }^{1}$ Ou Conferência das Nações Unidas sobre Desenvolvimento Sustentável (CNUDS), realizada entre os dias 13 e 22 de junho de 2012 na cidade brasileira do Rio de Janeiro.

${ }^{2}$ COP (Conference Of the Parties) número 19, organizada pelas Nações Unidas entre 11 e 22 de novembro 2013 em Varsóvia, Polónia.
} 
e Paterson (2010), sobre a legitimidade de governança climática global, e em particular o debate sobre os mercados de carbono (Lohmann, 2009, 2010, 2012; Paterson e Newell, 2012; Paterson, 2012). É minha convicção, no entanto, que a análise destes autores continua a ser demasiado restrita. Bodansky e Bernstein, por exemplo, utilizam uma abordagem institucionalista relativamente estreita, enquadrando as questões da legitimidade no contexto do enfraquecimento do Estado nacional e dos processos de globalização. Paterson (2010) amplia o debate, entrando na questão da tensão entre acumulação e legitimação e no duplo movimento de Karl Polanyi, mas a sua análise recusa reconhecer o caráter fundamental e estrutural da incompatibilidade a longo prazo entre a acumulação capitalista e o que é percebido como o bem comum. É esta incompatibilidade que determina a crise de legitimidade da governança capitalista (Lohmann, 2012). Nenhum dos autores traz uma visão holística de como o capitalismo cria problemas de legitimidade para as suas próprias estruturas de governança que organizam a socioecologia capitalista. É este assunto que pretendo abordar nesta contribuição teórica.

\section{O capitalismo e a legitimidade da governança global}

Legitimidade significa "direito de governar" (Bodansky, 1999) e assenta na aceitação compartilhada de regras e normas justificativas por parte das comunidades afetadas ou relevantes. É fundada na crença compartilhada de que "as ações de uma entidade são desejáveis, próprias ou apropriadas dentro de um certo sistema de normas, valores, crenças e definições, socialmente construídos." (Bernstein, 2004). Faz parte de uma construção ideológica fundada na convicção de que "a organização política existente é a mais adequada” e torna as existentes relações de poder aceitáveis (Lipset, 1959). É uma fonte de poder que permite certas políticas e práticas, ao mesmo tempo que pró́be outras (Bernstein, 2004). $\mathrm{Na}$ análise aqui apresentada usa-se a designada abordagem sociológica substantiva ou de "legitimidade popular", que centra a atenção nas atitudes dos sujeitos da autoridade. Nesta perspetiva, a legitimidade depende de atitudes práticas constituindo, portanto, um fenómeno empírico (Buchanan e Keohane, 2006).

Até muito recentemente o mundo académico ignorou a questão da legitimidade ao nível da governança internacional (Bodansky, 1999). A literatura mainstream assumia um modelo baseado no consenso, através do qual a questão da legitimidade era abordada a partir de uma perspetiva orientada para o Estado-nação, sendo que os Estados obedeciam aos tratados internacionais e as instituições internacionais eram consideradas fracas (Bodansky, 1999: 604-607). O enfoque nacional resultou da 
consideração de que é no Estado que se encontra não só o nível primário do uso legítimo da violência e do contrato social, mas também o principal nível de acumulação e legitimação (Paterson, 2010). A globalização conduziu o processo de acumulação ao nível global e, como consequência, a autoridade na tomada de decisões gravitou para o nível internacional. Nesse processo, a questão da legitimidade veio a surgir como uma questão de governança global (Bernstein, 2004; Bodansky, 1999: 596; Paterson, 2010).

Concordo com Jason Moore (2011: 107), quando este argumenta que o sistema-mundo moderno é uma ecologia-mundo capitalista, "um matrix histórico mundial de natureza humana e extra-humana, com a premissa da mercantilização infinita" (Moore, 2001: 136). A globalização capitalista neoliberal é apenas uma última fase deste processo de acumulação de capital (Baganha, 2001: 138), um processo hegemónico global, baseado na hegemonia do eixo Atlântico Norte, liderado pelos EUA e pela UE, e ideologicamente fundamentado no Consenso de Washington. ${ }^{3}$ A governança global é a institucionalização desta fase. As suas instituições são globais e hegemónicas, e os seus procedimentos e regras regulam e "facilitam a expansão do capitalismo global" (Santos, 2001: 92-93) e "reflectem os interesses dos países industriais avançados" (Stiglitz, 2007: 276). Exemplos dessas reflexões podem ser encontrados nos procedimentos de voto dessas mesmas instituições, na definição da agenda de trabalho e nos resultados das políticas.

Assim, os processos de acumulação de capital e da liberalização e criação de mercados são elementos vitais para compreender os movimentos cumulativos e cíclicos (Wallerstein, 2008) na história da ecologia-mundo capitalista e da sua interação com as suas próprias estruturas de governança.

A tensão central entre a acumulação e a legitimação é gerada através da distribuição mutuamente exclusiva do valor. Parte do valor que é gerado no processo da produção capitalista é necessário para a legitimação das desigualdades sociais e das relações de poder desiguais resultantes do mesmo. Este valor, no entanto, não pode ser reinvestido no processo produtivo da forma mais eficiente - do ponto de vista da acumulação de capital - e, portanto, restringe as possibilidades do processo de acumulação (Paterson, 2010: 349). Esta tensão traduz-se em crises de legitimidade inerentes a esse processo, que se expressam na forma de crises fiscais, crises de subconsumo, crises financeiras, entre outras (ibidem: 348-349). A atual crise da

\footnotetext{
3 O Consenso de Washington é um termo introduzido por John Williamson em 1989 para descrever a hegemonia neoliberal liderada por Washington, após o colapso da União Soviética (Williamson, 2009).
} 
governança manifesta-se através da crise da UE, do impasse das negociações da Organização Mundial do Comércio (OMC) e das dificuldades em resolver os problemas ambientais globais e as alterações climáticas (Dickenson, 2012: 50).

A perspetiva da centralidade da tensão entre acumulação e legitimação na reprodução de qualquer sociedade capitalista (Paterson, 2010) proporciona um método particularmente instrutivo para esclarecer a complexidade das relações socioecológicas ${ }^{4}$ do sistema capitalista e é particularmente importante para compreender as crises recorrentes (Arrighi, 1978: 3; Moore, 2011: 107) de cada tipo de governança capitalista (Habermas, 1975; Paterson, 2010).

De acordo com a teoria de Jürgen Habermas sobre a crise de legitimidade, em qualquer formação social com uma "contradição fundamental", na qual indivíduos e grupos se confrontam repetidamente com "reivindicações e intenções que são, a longo prazo, incompatíveis", a organização transpõe o potencial conflito para "a dimensão de gestão" (Habermas, 1975). Apesar de o conceito originalmente servir para explicar a crise de legitimação do Estado-Providência na Europa ocidental nos anos setenta, podemos observar mecanismos similares ao nível da governança global atual.

Enquanto esta incompatibilidade de reivindicações e intenções não é reconhecida pelos participantes, o conflito permanece latente, legitimado por uma justificação ideológica que oculta a distribuição assimétrica de oportunidades para satisfazer necessidades legítimas (ibidem). No entanto, quando confrontadas com as barreiras internas do processo de acumulação, as economias capitalistas entram em crise. Resultam crises de governação e da ideologia legitimadora, "já que a crise dos mecanismos de direção oferece uma crítica prática da ideologia que concebe o mercado como livre de poder" (ibidem). Assim, estas crises repolitizam a governança. Ao nível da governança global, esta repolitização significa uma subida à superfície das contradições fundamentais da estrutura social, nomeadamente dos conflitos entre classes e entre países (Dickenson, 2012: 49). Neste sentido, quando a economia-mundo estagna, significa que "o bolo geral está a encolher". A questão política que então se coloca é "quem deve suportar, no interior dos países e entre eles, o encargo desta retração” (Wallerstein, 2012).

\footnotetext{
${ }^{4}$ Prefiro utilizar socioecologia, como faz Moore (2011), em vez de socioeconomia.

5 A dimensão da gestão (Steuerung) de um sistema social diz respeito à sua "capacidade de manter as suas fronteiras e a sua existência pela dominação da complexidade de um ambiente inconstante" (Habermas, 1975: 4). Os mecanismos de gestão são, portanto, as instituições que governam o processo de reprodução capitalista.
} 


\section{Mecanismos da deslegitimação}

De acordo com a teoria de Habermas (1975), é possível distinguir forças, ou "mecanismos de transferência", que, numa crise de legitimidade, transferem as mudanças na conjuntura económica da socioecologia capitalista global das suas estruturas de governança existentes. Associadas a estas forças, tendem a ocorrer dois tipos diferentes de contestação, que Ronaldo Munck (2006: 9) designa por contestação tipo-Marx e contestação tipo-Polanyi. A primeira baseia-se na ideia de Karl Marx de que o desenvolvimento capitalista conduz ao desenvolvimento de novos poderes sociais (de classe) com novos interesses, que resultam numa nova luta pelo poder. A "contestação tipo-Polanyi" - inspirada na obra de Karl Polanyi - refere-se à consequência de resistências de grupos sociais que são vítimas do mercado global de autorregulação, e que pelas forças do mercado estão a perder os seus direitos e o seu poder (Munck, 2006).

\subsection{Marx - A mudança das relações de poder}

$\mathrm{Na}$ sua obra Contribuição para a crítica da economia política, Karl Marx afirmou que:

Numa certa etapa do seu desenvolvimento, as forças produtivas materiais da sociedade entram em contradição com as relações de produção existentes ou, o que é apenas uma expressão jurídica delas, com as relações de propriedade no seio das quais se tinham até aí movido. De formas de desenvolvimento das forças produtivas, estas relações transformam-se em grilhões das mesmas. [...] Com a transformação do fundamento económico revoluciona-se, mais devagar ou mais depressa, toda a imensa superstrutura. (1982; itálico do autor)

Várias teorias de Relações Internacionais com origem marxista e baseadas nesta ideia são importantes para a compreensão da dinâmica da governança global. Em particular mencionamos as teorias sobre o desenvolvimento desigual e combinado (Trotsky e Shachtman, 1996); as teorias sobre o imperialismo, como a de Lénine (1969); e as teorias do subimperialismo, como a de Marini (1972), que tenta combinar ambas. Com base nessas teorias, a contestação "tipo-Marx" tem origem na contradição fundamental entre as mudanças das forças produtivas e as formas sociais e políticas. Ao nível internacional, assume a forma de um conflito entre os Estados (Gill, 2004: 3), representando a contestação da legitimidade da ordem internacional vigente.

A reintrodução da teoria do subimperialismo de Ruy Mauro Marini (1972) por Böhm et al. (2012) é particularmente interessante para entender 
o papel das grandes potências emergentes como os BRICS. ${ }^{6}$ Esta teoria descreve o processo em que as economias historicamente dependentes atingem um certo nível de industrialização e de desenvolvimento de capital financeiro, que as leva a implementarem políticas expansionistas em relação a outras nações. ${ }^{7}$ A dinâmica do desenvolvimento desigual e combinado empurra-as para o núcleo desenvolvido do sistema-mundo, como tem acontecido com a Europa continental e os EUA nos últimos séculos (Trotsky e Shachtman, 1996: 15). As instituições de governança, que outrora representavam a cristalização de determinadas relações de poder entre as classes e nações, acabam por ficar sob pressão, por não acompanharem as mudanças de poderes. Uma das consequências atuais deste mecanismo é o discurso sobre o chamado "défice democrático da globalização" expressado pelos BRICS.

\subsection{Polanyi - A destruição do tecido social}

Karl Polanyi (1944) e uma série de teóricos mais recentes (Castles et al., 2011; Lohmann, 2010; Munck, 2006; Santos, 2001; Stiglitz, 2001) têm argumentado que a sociedade inevitavelmente se protege contra os perigos do livre-mercado. O "duplo movimento" original de Polanyi, em que a expansão do mercado e a proteção social obedecem a fases (Munck, 2006), repete-se recentemente numa terceira fase de (neo)liberalização e num quarto movimento protecionista (Castles et al., 2011; Lohmann, 2010).

O "terceiro movimento", a globalização neoliberal das últimas décadas, pode ser comparado à "primeira onda de liberalização" no terreno global (Munck, 2006: 178). A fim de restaurar o processo de acumulação, essa "onda" consiste na remoção de barreiras para o mercado e na criação de novos mercados. Nesta fase, a mobilidade de capitais foi incentivada, o comércio livre santificado e o trabalho tornado mais "flexível" (Castles et al., 2011; Munck, 2006). Entretanto o Estado de bem-estar está a ser desmontado.

De acordo com Polanyi (1944), o movimento de liberalização é contrariado por um "segundo movimento" da própria sociedade para proteger seu tecido social. No seu tempo, esta fase foi marcada pela ascensão dos movimentos populares de apoio ao socialismo e ao fascismo, que contestavam a legitimidade da ordem liberal. Hoje, um similar "quarto movimento” (Munck, 2006: 181) está a contestar a governança global neoliberal contemporânea.

\footnotetext{
${ }^{6}$ Brasil, Rússia, Índia, China e África do Sul.

7 Deve-se notar que tanto Böhm como Marini ressaltam a continuidade de um caráter dependente; as políticas expansionistas são direcionadas principalmente para os países periféricos.
} 
Por um lado, esta contestação consiste numa "alter-globalização progressista” (Chase-Dunn e Gills, 2003: 3-4), ou num "cosmopolitismo subalterno", que equivale a uma "organização transnacional da resistência [...] de grupos sociais que são vítimas de trocas desiguais provocadas pela globalização hegemónica" (Santos, 2001: 73). Este movimento é essencialmente um movimento emancipatório (Chase-Dunn e Gills, 2003: 3-4) e une as vítimas da globalização, os trabalhadores ocidentais ameaçados pela concorrência chinesa, os ecologistas, os agricultores dos países em desenvolvimento, etc. (Stiglitz, 2007: 7). Com início na cimeira da OMC em Seattle, em 1999 (Chase-Dunn e Gills, 2003; Stiglitz, 2007), continuou através de protestos contra cimeiras internacionais, do Fórum Social Mundial (Santos, 2001) e dos regimes antineoliberais da América Latina (Chase-Dunn e Gills, 2003: 12). A crise económica reforçou-a, através da Primavera Árabe, do movimento dos indignados, do movimento "Occupy", dos protestos de estudantes no Quebeque e da ascendência de Syriza na Grécia (Wallerstein, 2012).

Por outro lado, o mesmo fenómeno consiste num movimento antiglobalização reacionária protecionista e xenófobo, assente no nacionalismo de direita intolerante e no extremismo religioso (Chase-Dunn e Gills, 2003: 3-4; Munck, 2006: 182), que identifica a exclusão com estabilidade e coesão social. Expressa-se na ascensão eleitoral de populistas de direita na Europa do Norte e do movimento "Patriot" nos EUA (Munck, 2006), bem como no renascimento religioso no Médio-Oriente.

Estes dois lados do contramovimento exprimem soluções opostas para o problema de legitimidade: "as instituições internacionais devem tornar-se mais democráticas - opinião geralmente expressa pelos mais cosmopolitas -, ou os governos nacionais devem ser protegidos contra a usurpação - uma posição mais fortemente expressa por nacionalistas conservadores, como dos 'novos soberanistas' nos Estados Unidos” (Bernstein, 2004).

\section{Aplicação à governança climática global}

Estamos acostumados a pensar o capitalismo como um sistema social ou mesmo como um sistema exclusivamente económico. Para a análise da governança ambiental global, no entanto, uma abordagem socioecológica, como proposta por Jason Moore (2011), é crucial, sobretudo porque é impossível fazer uma distinção não arbitrária entre o capitalismo como sistema social e o seu meio ambiente. Assim, para esta abordagem, as estruturas de governança sob o sistema capitalista são principalmente instituições que regulam as relações entre o processo de acumulação capitalista e o seu socioambiente, estruturando as tensões entre a necessidade de acumulação de valor e a legitimação de sua existência. 
Crises sistémicas da socioecologia, como a que experimentamos hoje, emergem através do esgotamento dessas "estruturas organizacionais" que tinham inicialmente possibilitado o processo de acumulação (Arrighi, 1994; Moore, 2011). Na secção seguinte, este trabalho estuda a crise da deslegitimação da governança climática global na mesma base que outros campos da governança global da socioecologia global capitalista. Isto significa que o fracasso atual na resolução de problemas climáticos reflete o esgotamento das estruturas organizacionais que formam as interações dentro do sistema socioecológico capitalista.

Por motivos de análise, neste artigo distinguir-se-ão duas fases na crise de legitimação. A primeira é a fase da institucionalização e legitimação das estruturas de governança climática e dos mercados de carbono e a segunda consiste numa fase de deslegitimação. Pode considerar-se que estas fases são artificiais, uma vez que na prática a distinção é inexistente. Ambos os processos de legitimação e deslegitimação coexistem como dois lados num mesmo processo dialético. O caso do chamado capitalismo verde e a regulação do mercado de carbono é um exemplo típico disso, como mostra Paterson (2010). Outro é o comportamento dos BRICS na questão do clima (Bond, 2013: 252). No melhor dos casos, podemos distinguir uma fase onde a construção de legitimação é dominante, e uma na qual a legitimação é mais acentuadamente colocada em questão.

\subsection{Institucionalização e legitimação}

Como o sistema socioecológico capitalista é impulsionado principalmente pelo processo de acumulação, cria pressão para incluir neste processo novas e vastas áreas do planeta, penetrando nichos cada vez mais profundos da vida social e ecológica (Moore, 2008), que implicam relações cada vez mais expansivas em relação à natureza. $\mathrm{Na}$ fase de desenvolvimento mais recente, foi obrigado a encontrar novas estratégias, sob forma do neoliberalismo. Existe uma necessidade de perfurar cada vez mais profundamente o solo, em locais cada vez mais distantes, à procura de recursos como petróleo e água. Ao mesmo tempo, a biotecnologia e a engenharia genética abriram novas áreas de mercantilização, transformando organismos naturais em objetos passivos de manipulação, resultando num crescimento explosivo de plantas e animais geneticamente modificados (Moore, 2008; Zizek, 2011). Esta extensão do mercado coevoluiu com um grave aumento da injustiça e da exclusão socioecológica - Zizek (2007) chama isso de "novos apartheids" -, conduzindo à conversão de corpos humanos - especialmente os das mulheres, pessoas de cor, trabalhadores e agricultores - e dos seus ambientes em depósitos de lixo tóxico para uma ampla gama de substâncias cancerígenas e letais de outra forma (Moore, 2001: 136-137; 2008). 
Desde a sua ascensão, para responder aos problemas que o seu desenvolvimento trazia, o sistema capitalista teve necessidade de estruturas de governança para regular a sua própria sobrevivência e reprodução. A estes problemas economistas ortodoxos deram o nome de market-failures ou deficiências do mercado. Académicos marxistas chamaram-lhes as "contradições internas”, uma vez que estão associados ao desenvolvimento do próprio sistema capitalista, mas põem em perigo a sua própria reprodução. Exemplos são os aumentos das desigualdades sociais e de protestos, os monopólios, a rivalidade interimperialista e as chamadas "externalidades": poluição, alterações climáticas, desertificação, etc. Na sua fase inicial, o Estado desenvolvera um papel crucial enquanto estrutura de governança primária para superar essas contradições. Acompanhando a globalização da acumulação capitalista e o desmoronamento dos antigos impérios coloniais, agora as estruturas de governança global vieram regular a reprodução da socioecologia global capitalista. Como outros campos de política, as estruturas de governança ambiental foram-se adaptando ao Consenso de Washington. O Protocolo de Quioto e os mercados de carbono são exemplos típicos desta institucionalização (Brunnengraber, 2007). Mesmo não tendo os EUA assinado o tratado, o acordo de Quioto reflete os seus interesses (Böhm et al., 2012: 1621).

Antes da era neoliberal, os problemas ambientais do capitalismo eram regulados pelo princípio de "comando e controlo", uma institucionalização baseada principalmente em acordos multilaterais entre governos nacionais. Hoje, a governança ambiental é mais "multifacetada" (Andonova, Betsill e Bulkeley, 2009). O "compromisso de ambientalismo liberal" (Bernstein, 2004) é impulsionado principalmente por uma governança orientada para o mercado - chamada non-state-market-driven (NSMD). Isto significa a efetiva 'mercantilização' da governança ambiental global (Paterson, 2010: 348) e consiste num "novo regime de organização capitalista, cuja tarefa é a 'descarbonização' e o 'esverdeamento' da economia, com o mínimo de interrupção dos padrões de crescimento económico e expansão da economia global" (Böhm et al., 2012).

O discurso legitimador por trás dos mecanismos de governança dos problemas climáticos foi baseado na gestão e administração tecnocrática de especialistas. Eric Swyngedouw (2010) classifica esse discurso como pós-político, porque está "estruturado em torno de uma perceção da inevitabilidade do capitalismo e da economia de mercado como a estrutura organizacional básica da ordem social e económica, para a qual não há alternativa”.

A contestação e as lutas ideológicas e dissensuais foram evacuadas da política do possível e são substituídas pelo planeamento técnico-administrativo 
(Swyngedouw, 2010). Uma crítica semelhante é dada por Slavoj Zizek, que caracteriza a ideologia do "capitalismo verde" como "o novo ópio das massas" (Zizek, 2011). A lógica por trás desse discurso pós-político é o teorema de Coase (1960) - um teorema que provém da economia (neo)clássica -, que afirma que o estabelecimento de direitos de propriedade e da negociação entre os proprietários irá produzir os resultados mais eficientes na gestão de recursos (Dickenson, 2012: 42). Consequentemente, as políticas de governança devem consistir na aplicação de direitos de propriedade e incentivos de mercado para diminuir a poluição e permitir a sua negociação e a introdução de ecotaxas.

\subsection{Mercados de carbono}

O exemplo mais elaborado na literatura académica deste tipo de estruturas neoliberais no plano da governança climática é o chamado "mercado de carbono". Os mercados de carbono envolvem todo o tipo de regras e práticas regulamentadas de produção e consumo relacionadas com as emissões de carbono. Envolvem a governança orientada para o mercado, com base nos acordos internacionais sobre o clima, mas em termos menos estritos, e envolvem também os mecanismos tradicionais de mercado - como os mecanismos de definição de preço nos mercados de carvão e petróleo, os valores de stock das empresas de petróleo, etc. A maior parte da literatura académica sobre governança climática e os mercados de carbono concentra-se no primeiro tipo de estruturas.

Originalmente, o "mercado de carbono" referia-se ao mecanismo de cap and trade e aos mecanismos de "desenvolvimento limpo" elaborado em Quioto (Böhm et al., 2012), mas desde então tem sido usado para "referenciar o conjunto de práticas que procuram gerenciar as emissões de carbono de uma forma ou outra por meio de transações de mercado" (Paterson, 2010: 350-351; itálico do autor). Estes mecanismos envolvem sistemas de comércio de emissões, geração de relatórios, iniciativas de divulgação e criação de mercados de compensação (Böhm et al., 2012: 1620-1621; Paterson, 2010: 350-351). Juntos formam "a ferramenta político-económica fundamental no coração do capitalismo climático” (Böhm et al., 2012).

Cap and trade é um sistema de governação que coloca um limite nos direitos de emissão globais de todos os gases de efeito estufa (GEE) e, em seguida, distribui esses direitos às entidades poluidoras. Esses direitos podem depois ser negociados de acordo com as necessidades dos poluidores. Por exemplo, se uma entidade ultrapassar os limites aos quais tem direito, é forçada a comprar mais direitos de emissão de carbono no mercado. Se, no entanto, o poluidor reduzir as suas emissões, pode vender esses mesmos direitos de 
poluição no mercado. Desta maneira, incentivam-se empresas e indústrias inteiras a tomar decisões de forma a alcançar os objetivos da maneira mais económica possível (Böhm et al., 2012; Lohmann, 2010). O pressuposto subjacente a esta mercantilização do ciclo do carbono é, portanto, que os mecanismos de mercado permitam a redução das emissões, da forma mais eficiente do ponto de vista económico.

O Mecanismo de Desenvolvimento Limpo (MDL) é um mercado compensatório de carbono (Carbon Offset Market) coordenado pelas Nações Unidas. Este tipo de mercado permite aos "países industriais desenvolvidos e às suas empresas comprarem créditos de carbono de projetos do chamado "desenvolvimento limpo" localizados no Sul Global". A ideia é que esses projetos, por meio de financiamento do mercado offset, permitam formas "limpas" de desenvolvimento, no que toca às suas pegadas de carbono (Böhm et al., 2012).

Recentemente, empresas privadas, em particular investidores financeiros, desenvolveram mecanismos semelhantes. Estes são os chamados mercados compensatórios voluntários (Voluntary Offset Markets - VOM). Um dos mais conhecidos é a ClimateCare, uma das maiores empresas do mundo em consultoria de carbono, propriedade de JPMorgan Chase. Através destes mecanismos, a Land Rover, por exemplo, pode alegar que a fabricação dos seus carros é neutra em carbono, já que a ClimateCare, em nome da Land Rover, investe em projetos como caldeiras de alta pressão de biomassa na Argentina ou fazendas eólicas na China (Böhm et al., 2012; Lohmann, 2010).

Todos esses mecanismos de governança implicam a criação de novas mercadorias e fontes de lucro ou a gestão de risco de investimentos existentes (Paterson 2010: 359). Diferentes autores (Ghosh e Yasmin, 2011; Lohmann, 2009, 2010; Stern, Campanale e Legget, 2013) fazem uma comparação interessante e reveladora entre os mercados de compensação de carbono e os mercados de derivativos financeiros. Estes não só consistem em produtos da institucionalização do novo capitalismo neoliberal e das suas novas estruturas de governança, mas também numa resposta temporária desenvolvida pelo neoliberalismo para enfrentar os problemas de governança. Enquanto a liberalização dos mercados financeiros foi a resposta neoliberal à crise económica estrutural dos anos setenta e oitenta, tendo a criação maciça de crédito funcionado como resposta à falta de investimento e demanda de mercado -, os mercados de carbono têm sido desenvolvidos desde a década de 1990 como uma resposta aos alertas emergentes do meio científico sobre a mudança climática.

Como os valores de mercado e a quantidade de investimentos representam de certa forma a confiança dos investidores em ativos específicos, 
a relevância dos mecanismos de governança climática é parcialmente revelada através dos valores de mercado. Juntos, os mercados de carbono foram avaliados em US \$ 141,9 biliões em 2010 (World Bank, 2012), embora a maior parte consista na negociação do Sistema Europeu de Comércio de Emissões (Emission Trade System - ETS). De acordo com as estatísticas do MDL, mais de 5600 projetos do MDL estão em andamento, com previsão de produzir mais de 2 biliões de unidades de Redução Certificada de Emissões (RDEs ou Certified Emission Reduction Units - CERs) em 2012 (Böhm et al., 2012). Entre 2002 e 2010, o valor total das transações no mercado primário do MDL, de acordo com cálculos do Banco Mundial, foi de aproximadamente US $\$ 27$ biliões (ibidem).

Embora apresentados como "soluções de soma positiva", esses mecanismos são desenhados principalmente pelos e para os países industrializados do Norte Global. O objetivo principal "não é reduzir as emissões de gases de efeito estufa o mais rápido possível, mas, pelo contrário, preservar os interesses dos países dependentes de combustíveis fósseis e as suas empresas multinacionais, em particular os setores da indústria pesada, de energia e de combustíveis fósseis" (Böhm et al., 2012: 8). O seu efeito sobre a governança ambiental foi a promoção de mecanismos de mercado, as políticas de privatização dos bens comuns globais e a criação de direitos de propriedade privada sobre os recursos naturais (Bernstein, 2004: 158). "Elas representam uma extensão do poder do capital; implicam um aumento do poder dos países dominantes e suas elites em relação aos subordinados em todo o mundo e um agravamento das desigualdades globais" (Böhm et al., 2012: 158). Na verdade, a maioria destes projetos são "negócios do costume" (Lohmann, 2009: 2) e, muitas vezes, simplesmente criam oportunidades de lucro adicionais para uma série de projetos de investimento e infraestruturas já existentes, incluindo até projetos ambientalmente destrutivos como barragens (Böhm et al., 2012). Isto leva autores como Ghosh e Sahu (2011) a concluir que o MDL subsidia e legitima a poluição corporativa.

\subsection{A deslegitimação}

O "acordo do ambientalismo liberal" 8 está institucionalizado desde a Conferência do Rio de 1992 (Bernstein, 2001). Este paradigma de governança ambiental, que permitiu a incorporação do ambiente nos mercados

\footnotetext{
8 'Compromise of liberal environmentalism' é um conceito de Bernstein (2001), por vezes traduzido por "compromisso" ou "acomodação" do ambientalismo liberal. No entanto, julgo que nenhuma destas duas traduções é adequada, já que "compromise" incorpora a ideia de uma institucionalização de interesses opostos.
} 
liberais, agora enfrenta problemas de legitimidade. Com a crise atual, a governança baseada na cooperação entre as várias grandes potências do sistema mundial capitalista está a desmoronar-se rapidamente. Esta situação pode ser parcialmente explicada pelo colapso da União Soviética, que resultou no desaparecimento do inimigo comum das economias capitalistas e na eliminação de uma ameaça para a sua sobrevivência. Hoje é agravada pela crise económica mundial, que leva novamente à predominância do confronto entre rivais imperialistas (Dickenson, 2012).

A crise é a exaustão das relações que regulam a reprodução das naturezas biofísicas e humanas, iniciadas pelo regime de acumulação. Materializa-se quando o sistema atinge os seus limites socioecológicos e desaparece a sua capacidade para manter o equilíbrio entre os elementos interdependentes. Estes limites assumem várias formas: desde a regulação pelo Estado9 e os movimentos antissistémicos ao desmatamento e às mudanças climáticas (Moore, 2011: 123). É neste contexto que a teoria da crise de legitimação de Jürgen Habermas (1975) se torna relevante.

Com o capitalismo em crise, os mecanismos do mercado e as estruturas mais restritas da governança climática estão a sofrer estes problemas da crise de legitimação. O recente relatório de Stern de 2013, por exemplo, alerta para os riscos acumulados, bolhas, mentalidades de curto prazo e para a possibilidade de uma grande crise económica nos mercados globais de carbono (Stern et al., 2013), que designa como a "bolha de carbono". A principal ideia por trás da "bolha de carbono" é a de que os mercados de carbono, e particularmente os preços das ações de empresas de energia, estão sobrevalorizados porque não levam em conta os limites que terão de ser impostos pela governança climática. De acordo com este relatório, apenas $31 \%$ das reservas comprovadas de petróleo podem ser exploradas e queimadas, para ter uma hipótese de $80 \%$ de manter o aquecimento global abaixo dos $2^{\circ} \mathrm{C}$ de aumento de temperatura concordados. O banco Hong Kong and Shanghai Banking Corporation (HSBC), por exemplo, advertiu que 40-60\% da capitalização de mercado das empresas de petróleo e gás estava em risco da bolha de carbono. Os mercados de ações estão de facto a apostar na inação dos países sobre mudanças climáticas (Carrington, 2013).

Em relação às estruturas mais restritas, como o MDL e o comércio de emissões, Lohmann (2009) e Gosh e Sahu (2011) alertam que há perigos

\footnotetext{
${ }_{9}$ O excesso da regulação estatal tende a restringir as possibilidades de acumulação; leva às "greves de investimento", às desvantagens competitivas do mercado nacional, e ao crowding-out. Portanto restringe as possibilidades de sua própria reprodução e até mesmo a sua própria sobrevivência.
} 
semelhantes. Verifica-se um número crescente de críticas no mundo acadêmico/científico: os abusos de poder e de riqueza são uma componente técnica integral da formação de mercadorias. Isto leva Lohmann a concluir que o carbono é um produto que não pode ser regulado e cuja administração é intrinsecamente corrupta (2009: 2-5). Por esse motivo, os seus problemas só podem ser resolvidos através da eliminação do próprio mercado. Até a imprensa está cada vez menos confiante nos mercados de carbono e na atual regulação climática (ibidem: 3). Esta deslegitimação é igualmente expressa na falta de confiança nos mercados financeiros, como se verificou, por exemplo, na queda recente e brusca dos mercados de carbono entre 2008 e 2013, em que os valores dos direitos de emissão diminuíram de $€ 33$ por tonelada para menos de $€ 3$ por tonelada (Bond, 2013: 264).

Defendo que esta deslegitimação é expressa pela paralisação das negociações sobre o clima, devido aos conflitos entre potências imperialistas e pela retórica crescente do movimento de justiça ambiental global contra a governança climática global neoliberal. Ambos os mecanismos, porém, influenciam-se reciprocamente: as dinâmicas imperialistas influenciam as condições de vida que podem criar a base de movimentos sociais, enquanto os movimentos populares anticapitalistas podem influenciar o comportamento dos Estados na esfera das relações internacionais.

\subsubsection{O estrangulamento pelo imperialismo}

Embora os representantes das classes capitalistas ao nível internacional reconheçam a existência de um abismo iminente e que os custos a longo prazo do aquecimento global excedem em muito os custos imediatos de mitigação, são incapazes de tomar uma ação decisiva (Dickenson, 2012). Esta situação resulta essencialmente das dinâmicas imperialistas e subimperialista, nomeadamente da divergência de interesses vitais entre as diferentes classes capitalistas nacionais, particularmente entre as novas economias crescentes e as antigas. As 147 empresas multinacionais que controlam 40 por cento da riqueza mundial e dominam a economia mundial resistem ferozmente a qualquer intervenção que possa ameaçar os seus lucros no curto prazo, como legislação ambiental que reduza a sua competitividade, e esperam que os seus "países de origem" as apoiem (Dickenson, 2012: 51). Esta situação é agravada pela pior crise financeira da história (Böhm et al., 2012; Dickenson, 2012; Neale, 2010).

Isso explica a oposição dos EUA aos acordos climáticos vinculativos, mas também a resistência das novas potências económicas em ascensão. Os BRICS, como estados subimperialistas, "procuram cada vez mais oportunidades de investimento em outros mercados periféricos, precipitando 
processos de acumulação por despossessão dentro de suas esferas de influência" (Böhm et al., 2012; Bond, 2013). No que diz respeito à governança do clima, estas potências emergentes convergiram na sabotagem de qualquer regulação ecológica viável à escala global (favorecendo a crescente mercantilização através do comércio de emissões). Enquanto potências europeias, tendem a utilizar a regulamentação climática para proteger a sua própria indústria (Orbie, 2008), cálculos procorporativos também guiam a diplomacia climática dos países emergentes, exigindo apenas maiores cortes de emissões nos países industrializados do Norte (Bond, 2013).

A China, por exemplo, não está apenas extensivamente a investir em terra arável africana e nas indústrias extrativas (ibidem), como vê também a questão da mudança climática como uma questão de importância estratégica global. As negociações sobre os regimes pós-Quioto representam uma oportunidade para exercer o seu poder na criação de regras e instituições sobre as grandes questões globais (He, 2010). O mesmo se aplica ao Brasil, cuja alavancagem do mecanismo de desenvolvimento limpo é caracterizado por Böhm et al. (2012) e Bond (2013) como uma forma de expansão subimperialista. Estes países, mais que nunca integrados na economia mundial, exigem alterações às estruturas de governança com vigor renovado (Bernstein, 2004: 143).

Quando a institucionalização existente deixa de refletir o equilíbrio de poderes entre os atores, isto leva ao confronto com as instituições lideradas por Washington, como o FMI e a OMC (Bond, 2013). Aspeto que explica a retórica "anti-imperialista" e as ações diplomáticas, por exemplo, no Conselho de Segurança das Nações Unidas, desses poderes emergentes subimperialistas (ibidem). A consequência é a perda de legitimidade dos mecanismos de governança internacionais liderados pelo consenso de Washington. O fracasso da adaptação de governança climática global existente à nova configuração do poder, a fim de resolver os problemas climáticos comuns, é ilustrado pelos diferentes fracassos das negociações sobre o clima e pela não implementação dos acordos alcançados. O protocolo de Quioto, por exemplo, que iria implementar os resultados das primeiras negociações na Cúpula Mundial sobre Desenvolvimento Sustentável de 1992, no Rio do Janeiro, foi um fracasso total (Dickenson, 2012; Sachs, 2012). Foi incapaz de parar um aumento inexorável na emissão de gases de efeito estufa, ainda que praticamente nenhuma redução real tivesse que ser feita em relação ao nível de emissões em 1997, data em que o tratado foi assinado. Um dos fatores mais importantes foi o facto de os principais emissores de carbono, os EUA e a China, se terem recusado a participar (Dickenson, 2012). 
A Conferência de Copenhaga deveria resolver as limitações de Quioto e garantir a sua continuidade quando o tratado expirasse em 2012 (Dickenson, 2012). No entanto, o encontro ficou aquém das expectativas do mundo, já que nenhum documento juridicamente vinculativo foi aprovado, revelando outra vez o intenso conflito de interesses entre os principais Estados-nação imperialistas (He, 2010). A oposição dos EUA, que recusa uma desregulação vantajosa ao seu principal rival estratégico emergente, será sempre um grande obstáculo a qualquer acordo sobre o aquecimento global (Dickenson, 2012: 53).

A Rio+20, a recém-realizada cimeira da ONU, mostrou a mesma incapacidade dos dirigentes políticos para resolverem as atuais crises ecológicas, económicas, sociais e institucionais. Mais uma vez, o compromisso acordado reflete apenas os estreitos interesses nacionais (Beys, Coolsaet e Holemans, 2012). As potências ocidentais estavam interessadas em responder ao agravamento da crise financeira, as potências emergentes concentraram-se no seu crescimento e os países em desenvolvimento estão fartos de promessas não cumpridas. $O$ fracasso total é ilustrado pelo facto de que os principais líderes mundiais, como Barack Obama, Angela Merkel e David Cameron, nem sequer terem aparecido para as negociações (Samyn, 2012).

\subsubsection{O quarto movimento}

O segundo mecanismo de deslegitimação de governança global do clima é a sua contestação de baixo para cima, principalmente pelas vítimas do capitalismo global neoliberal e pelo aumento da mercantilização e da mercadorização nas áreas relacionadas com o clima (Lohmann, 2010). É uma contestação pelos perdedores das atuais estruturas de governança liberais e dos seus fracassos; são as vítimas da padronização de cultivos e florestas, vítimas das crescentes desigualdades entre os produtores, vítimas da "externalização" da poluição, refugiados do clima... Este movimento - o que poderia ser chamado de (quarto) movimento Polanyiano - encontra expressão no chamado Movimento de Justiça Ambiental, ou, mais especificamente, no Movimento de Justiça Climática na questão da governança climática. Rejeita padrões de ecoimperialismo, o uso desigual de materiais e combustíveis fósseis, deslocalizações, exportação de resíduos e soluções capitalistas ou de mercado (Chatterton, Featherstone e Routledge, 2013). A atual governança climática também é acusada de ser uma forma de neocolonialismo (Harvey, 1999; Paterson, 2010), uma vez que desloca os encargos do clima para o Sul, em nome da eficácia de custo (Lohmann, 2009: 7). De acordo com este ponto de vista, a análise económica ambiental neoclássica "especializada" serve como justificativa para a exportação de resíduos para países periféricos, 
como é demonstrado por um memorando interno do Banco Mundial escrito pelo então economista principal Lawrence Summers. ${ }^{10}$ Este memorando defende que a exportação de resíduos é eficiente com base (1) no menor custo de mortalidade resultante de rendimentos médios mais baixos no mundo neocolonial, (2) na "subpoluição", devido à relativa subpopulação nos países africanos para exemplo, e (3) na alta elasticidade-rendimento da demanda de um ambiente limpo ${ }^{11}$ por razões estéticas ou de saúde (Harvey, 1999: 153-154).

O movimento questiona também extensamente a legitimidade dos mercados de carbono. Apoiado por um número cada vez maior de autores (Böhm et al., 2012: 1623; Lohmann, 2009, 2010), o Movimento de Justiça Ambiental afirma que os mercados não trazem solução, são inerentemente corruptos e têm até mesmo efeitos particularmente negativos sobre o meio ambiente e as populações mais pobres do Sul Global (Harvey, 1999). Os mercados de compensação abrem a possibilidade de adquirir "créditos" para poluir, através de investimentos em projetos de redução de emissões nos países em desenvolvimento. Os seus críticos chamam-lhes uma forma moderna de venda de indulgências, tal como a prática introduzida pela Igreja católica durante a Baixa Idade Média de "vender perdão" pelos pecados, concedendo acesso ao céu (Paterson, 2010: 351).

Os mercados de compensação (offset-markets) são também acusados dessa lógica neocolonial por outros motivos. Não só evitam tomar medidas de redução de emissões no Norte, como impõem custos encobertos ao Sul. Os projetos de investimento ligados a esses mercados de compensação, por exemplo, requerem uma forte responsabilização "das populações do Sul e dos governos aos investidores ocidentais", perdendo parte da sua soberania neste processo (Bond, 2011; Paterson, 2010). Além disso, estes investimentos, por exemplo dentro do programa REDD (Redução de Emissões por Desmatamento e Degradação Florestal), do Banco Mundial, muitas vezes provocam o deslocamento e a expropriação das populações indígenas e os habitantes da floresta (Bond, 2011: 6; Paterson, 2010; Solon, 2010) e causam mortes, despejos violentos, violações dos direitos humanos, ameaças à sobrevivência cultural, e muitas vezes conduzem à militarização e servidão (Bond, 2011). Os críticos também acusam os países ocidentais de

\footnotetext{
${ }^{10}$ Memorando interno do Banco Mundial (Summers, 1992).

${ }^{11}$ A "elasticidade-rendimento de um ambiente limpo" é a relação entre a 'quantidade' de meio ambiente que a população local estaria disposta a sacrificar por dólar de aumento da sua renda. Como a renda média em muitos países neocoloniais é baixa, e um dólar significaria um aumento relativo maior na sua riqueza, a teoria económica neoclássica prevê que a quantidade de sacrifício do meio ambiente seja maior nesses países.
} 
uma apropriação indevida de um bem público global, sob forma do ciclo global de carbono - a capacidade de absorção de carbono da biosfera e de o transformarem num mercado dominado, sendo nada menos que "a colonização do céu" (Bond, 2011; Welz, 2009).

Os danos criados pela governança global capitalista "geram solidariedades entre lutas localizadas de forma diferente, e estas solidariedades têm o potencial de mudar os termos do debate sobre a mudança climática" (Chatterton et al., 2013). Como consequência, o movimento pela justiça climática consiste em redes diferenciadas, que se sobrepõem ou que são muitas vezes divergentes, que interagem e competem, mas que estão todas preocupadas com as questões da mudança climática (ibidem: 613). Têm em comum o facto de contestarem o consenso e a governança dominante, ligando questões de injustiça social à dominação económica e à destruição ecológica, defendendo alternativas baseadas na participação, na sustentabilidade ecológica e na justiça social (Chatterton et al., 2013). Mobilizadas em torno dos problemas ambientais, dão poder aos sem-poder e colocam as desigualdades socioecológicas no topo da agenda ambiental (Harvey, 1999), tratando efetivamente a destruição socioeconómica e ambiental como questões socioecológicas.

O Movimento de Justiça Climática manifestou-se em diversas mobilizações internacionais, de que são mais conhecidas as manifestações na Cimeira COP15 $5^{12}$ de Copenhaga. Nestas incluíam-se entre outros atores, o acampamento para a Camp for Climate Action, a Climate Justice Now Network, a Climate Justice Action, movimentos populares do Sul, como a Via Campesina (uma rede de camponeses), várias ONGs, sindicatos, organizações políticas, etc. (Chatterton et al., 2013: 605). Mobilizações posteriores sob a bandeira da justiça climática foram realizadas na Conferência Mundial dos Povos sobre as Mudanças Climáticas e os Direitos da Mãe Terra na Bolívia em 2010, e nas mobilizações durante a COP16 em Cancun, e a COP17 em Durban.

\section{Conclusões}

Esta análise mostrou que os problemas contemporâneos da legitimidade da governança climática global - como de resto os da governança global em geral - podem ser ligados a dois mecanismos que provocam a sua contestação. Estes mecanismos analíticos, inerentes ao funcionamento da socioecologia capitalista, são a rivalidade (sub)imperialista e a destruição

\footnotetext{
12 COP 15, organizada pelas Nações Unidas em dezembro 2009 em Copenhaga, Dinamarca, com o intuito de encontrar um acordo sobre a emissão de gases de efeito estufa (GEE). Foi seguida pela COP16 em Cancun e a COP17 em Durban.
} 
do tecido social. Ambos provocam uma contestação das estruturas organizacionais estabelecidas que regem as relações inter-humanas e extra-humana dentro da socioecologia capitalista global. Munck (2006) chama-as respetivamente contestação do tipo-Marx e do tipo-Polanyi. No caso da governança climática, estes movimentos são representados, por exemplo, pela recusa persistente das velhas e emergentes grandes potências em chegar a um consenso nos acordos climáticos por um lado, e por outro lado pela ascensão do movimento pela justiça ambiental.

As mobilizações da justiça climática mostraram que existem antagonismos de baixo para cima no debate sobre governança nesta área. Chatterton et al. (2013) mostram que, juntamente com a rivalidade imperialista, desafiam a ideia a que Swyngedouw (2010) chama o "consenso pós-político" na gestão neoliberal do clima.

A legitimidade das estruturas de governança é importante, não só do ponto de vista normativo, mas também para os resultados práticos das políticas. Se a governança climática global não consegue afirmar-se como legítima, a implementação de medidas que poderiam deter o aquecimento global ou compensar as vítimas é impossibilitada e as iniciativas já tomadas são prejudicadas. A falta de credibilidade e de legitimidade dos créditos de carbono, por exemplo, prejudicam os mercados de carbono, colocando em risco todos os investimentos já realizados e os retornos esperados sobre o investimento até mesmo a sua existência (Paterson, 2010: 360).

Para continuar a funcionar, a ecologia-mundo necessitará de novas formas de governança. As fases contínuas de acumulação de capital à escala global e as ondas de resistência contra essa acumulação criam um padrão de ondas de legitimação e deslegitimação na governança global. Estas desempenham um papel crucial na produção do futuro do sistema mundial. A sua análise é considerada crucial para entender a evolução do seu passado, presente e futuro (Chase-Dunn e Gills, 2003: 6). O consenso organizacional, assente no Consenso de Washington - imperialista e neoliberal -, tem sido severamente questionado nos últimos anos. No entanto, parece que as suas políticas são reforçadas também pelos novos atores internacionais (Bond, 2013). Revoluções organizacionais dão origem a novos regimes de acumulação (Moore, 2011: 122), mas enquanto estes serão baseados na acumulação capitalista, a tensão entre a necessidade de acumulação e legitimação encontrará apenas soluções temporárias (Paterson, 2010), implicando, em todas as novas fases, relações de exploração da natureza cada vez mais amplas e mais intensas (Moore, 2001).

Este ensaio tentou mostrar a importância das lutas de poder e do conflito de interesses na formação e na legitimação dos mecanismos de governança 
climática global. No entanto, há muito pouca literatura que investigue este caráter dialético do sistema de governança global. Este ponto de vista deve ser aprofundado em análises futuras, particularmente na comparação entre os mercados de carbono e os mercados financeiros. Na procura de soluções para a gestão do clima, este tipo de análise é crucial para evitar a ideia de que existem soluções técnicas, neutras ou pós-políticas.

\section{Referências bibliográficas}

Andonova, L. B.; Betsill, M. M.; Bulkeley, H. (2009), “Transnational Climate Governance”, Global Environmental Politics, 9(2), 52-73. DOI:10.1162/glep.2009.9.2.52

Arrighi, G. (1978), "Towards a Theory of Capitalist Crisis", New Left Review, 111(3), 3-24. Consultado a 20.07.2012, em http://www.soc.jhu.edu/people/Arrighi/publications/2003_Arrighi_Towards_Theory_Captialist_Crisis.pdf.

Arrighi, G. (1994), The Long Twentieth Century: Money, Power, and the Origins of our Times. Verso Books. Consultado a 20.07.2012, em http://books.google.com/books? $\mathrm{hl}=\mathrm{nl} \& \mathrm{l} \mathrm{r}=\& \mathrm{id}=\mathrm{cFfKtpgn} 4 \mathrm{fkC} \& \mathrm{oi}=\mathrm{fnd} \& \mathrm{pg}=\mathrm{PP} 11 \& \mathrm{dq}=$ arrighi+long + twentieth $+\mathrm{ce}$ ntury\&ots=DoamWcsQNE\&sig=pDSAHDIuhP7DXyNDo1DqqFupcug.

Baganha, M. I. (2001), "A cada sul o seu norte: dinâmicas migratórias em Portugal", in Boaventura de Sousa Santos (org.), Globalização: fatalidade ou utopia. Porto: Afrontamento, 135-159.

Bernstein, S. (2001), The Compromise of Liberal Environmentalism. New York: Columbia University Press. Consultado a 20.07.2012, em http://books.google.com/books?hl=nl\&lr $=\& \mathrm{id}=$ WVM7IPEaik8C\&oi=fnd\&pg=PR7\&dq=compromise + of + liberal++environmen talism+bernstein\&ots=b-QVEsWJRc\&sig=mHC-m-_BDFGpV5i9auyp0HoBY64.

Bernstein, S. (2004), "Legitimacy in Global Environmental Governance", Journal of International Law E International Relations, 1(1-2), 139-166.

Beys, O.; Coolsaet, B.; Holemans, S. (2012), "Rio+20: van mislukking naar succes? ”, MO.be, 25.06.2012. Consultado a 20.07.2012, em http://www. mo.be/opinie/rio20-van-mislukking-naar-succes.

Bodansky, D. (1999), "The Legitimacy of International Governance: A Coming Challenge for International Law?", American Journal of International Law, 93(3), 596-624.

Böhm, S.; Misoczky, M. C.; Moog, S. (2012), "Greening Capitalism? A Marxist Critique of Carbon Markets”, Organization Studies, 33(11), 1617-1638. DOI:10.1177/0170840612463326.

Bond, P. (2011), "From Copenhagen to Cancún to Durban: Moving Deckchairs on the Climate Titanic", Capitalism Nature Socialism, 22(2), 3-26.

Bond, P. (2013), "Sub-imperialism as Lubricant of Neoliberalism: South African 'Deputy Sheriff' Duty Within Brics”, Third World Quarterly, 34(2), 251-270. DOI:10.1080/01436597.2013.775783. 
Brunnengraber, A. (2007), "The Political Economy of the Kyoto Protocol”, Socialist Register, 43, 213-230.

Buchanan, A.; Keohane, R. O. (2006), "The Legitimacy of Global Governance Institutions", Ethics E International Affairs, 20(4), 405-437.

Carrington, D. (2013), "Carbon Bubble Will Plunge the World into another Financial Crisis - Report”, The Guardian, 19 de abril. Consultado a 12.05.2013, em http://www. guardian.co.uk/environment/2013/apr/19/carbon-bubble-financial-crash-crisis.

Castles, S.; Cubas, M. A.; Kim, C.; Koleth, E.; Ozkul, D.; Williamson, R. (2011), “Karl Polanyi's Great Transformation as a Framework for understanding Neo-Liberal Globalisation”. Consultado a 19.06.2012, em http://sydney.edu.au/arts/transformation_migration/downloads/STIM_WP1_Final.pdf.

Chase-Dunn, C.; Gills, B. (2003), “Understanding Waves of Globalization and Resistance in the Capitalist World (-)System: Social Movements and Critical Global (ization) Studies”. Consultado a 11.06.2012, em http://escholarship.org/uc/item/0p5244s1.

Chatterton, P.; Featherstone, D.; Routledge, P. (2013), “Articulating Climate Justice in Copenhagen: Antagonism, the Commons, and Solidarity”, Antipode, 45(3), 602-620. DOI:10.1111/j.1467-8330.2012.01025.x

Coase, R. H. (1960), "The Problem of Social Cost", in D. A. Wittman (org.), Economic Analysis of the Law: Selected Readings. Oxford: Blackwell Publishing Ltd, 1-13. Consultado a 16.07.2012, em http://onlinelibrary.wiley.com/doi/10.1002/9780470 752135.ch1/summary.

Dickenson, P. (2012), Planning for the Planet: How Socialism Could Save the Environment. Socialist Publications Ltd.

Ghosh, S.; Sahu, S. (2011), The Indian Clean Development Mechanism (CDM): Subsidizing and Legitimizing Corporate Pollution. West-Bengal, India: Sasanka Dev.

Ghosh, S.; Yasmin, H. (2011), "Clean Development Mechanism in India. A Country Overview”, in Soumitra Ghosh e Subrat Kumar Sahu (orgs.), The Indian Clean Development Mechanism (CDM): Subsidizing and Legitimizing Corporate Pollution. West-Bengal, India: Sasanka Dev, 1-34.

Gill, S. (2004), Final Pre-Translation Draft "International Relations/internationale Beziehungen”, in Wolfgang Fritz Haug (org.), Historisch-kritisches Wörterbuch des Marxismus. Vol. VI: Hegemonie-Justiz. Berlin/Hamburg, Argument Verlag. Consultado a 13.07.2012, em http://www.stephengill.com/ikrit_dictionary_final_ 2002.pdf.

Habermas, J. (1975), Legitimation Crisis. Tradução de T. Mccarthy. Boston: Beacon Press.

Harvey, D. (1999), “The Environment of Justice”, in F. Fischer e M. A. Hajer (orgs.), Living with Nature: Environmental Politics as Cultural Discourse. Oxford: Oxford University Press: 153-186. Consultado a 20.07.2012, em http://www.questia.com/ googleScholar.qst?docId=22772676. 
He, L. (2010), “China's Climate-change Policy from Kyoto to Copenhagen: Domestic Needs and International Aspirations", Asian Perspective, 34(3), 5-33.

Leahy, S. (2013), "Rich Countries Drag Feet at Climate Talks", IPS, 7 de maio. Consultado a 15.05.2013, em http://www.ipsnews.net/2013/05/rich-countries -drag-feet-at-climate-talks/.

Lénine, V. I. (1969), Imperialism, the Highest Stage of Capitalism: A Popular Outline. International Publishers.

Lipset, S. M. (1959), "Some Social Requisites of Democracy: Economic Development and Political Legitimacy”, The American Political Science Review, 53(1), 69-105. DOI:10.2307/1951731

Lohmann, L. (2009), "Regulation as Corruption in the Carbon Offset Markets - Cowboys and Choirboys", site The Corner House, 8 de junho.

Lohmann, L. (2010), "Uncertainty Markets and Carbon Markets: Variations on Polanyian Themes”, New Political Economy, 15(2), 225-254. DOI:10.1080/13563460 903290946.

Lohmann, L. (2012), “A Rejoinder to Matthew Paterson and Peter Newell”, Development and Change, 43(5), 1177-1184. DOI:10.1111/j.1467-7660.2012.01795.x

Marini, R. M. (1972), "Brazilian Subimperialism”, The Monthly Review, 23, 14-24.

Marx, K. (1982), "Prefácio", in Para a Crítica da Economia Política. Lisboa/Moscovo: Editorial Avante/Edições Progresso. Tradução de José Barata-Moura [ed. orig.: 1859]. Consultado a 24.09.2012, em http://www.marxists.org/portugues/marx/1859/01/ prefacio.htm.

Moore, J. W. (2001), “Marx's Ecology and the Environmental History of World Capitalism", Capitalism Nature Socialism, 12(3), 134-139.

Moore, J. W. (2008), "Ecological Crises and the Agrarian Question in World-historical Perspective”, Monthly Review, 60(6), 54-63.

Moore, J. W. (2011), "Ecology, Capital, and the Nature of our Times: Accumulation and Crisis in the Capitalist World-ecology”, Journal of World-systems Research, 17(1), 107-147.

Munck, P. R. (2006), "Globalization and Contestation: a Polanyian Problematic", Globalizations, 3(2), 175-186.

Neale, J. (2010), “Climate Politics after Copenhagen”, International Socialism. A Quarterly Journal of Socialist Theory, 126. Consultado a 19.07.2012, em http://www.isj.org.uk/ index.php4 ? $\mathrm{id}=637 \&$ issue $=126 \& \mathrm{ref}=\mathrm{nf}$.

Orbie, J. (2008), Europe's Global Role: External Policies of the European Union. Surrey: Ashgate Publishing.

Paterson, M. (2010), "Legitimation and Accumulation in Climate Change Governance", New Political Economy, 15(3), 345-368.

Paterson, M. (2012), "Who and What are Carbon Markets for? Politics and the Development of Climate Policy”, Climate Policy, 12(1), 82-97. DOI:10.1080/14693062.2011.579259. 
Paterson, M.; Newell, P. (2012), "Of Heroes, Villains and Climate Capitalism: A Response to Larry Lohmann”, Development and Change, 43(5), 1171-1175. DOI: 10.1111/j.1467-7660.2012.01796.x.

Polanyi, K. (1944), The Great Transformation. New York: Ferris Printing Company.

Sachs, J. (2012), “A Rio Report Card”, Aljazeera, 19 de junho. Consultado a 19.06.2012, em http://www.aljazeera.com/indepth/opinion/2012/06/2012619131241353443.html.

Samyn, S. (2012), "Rio+20 dreigt klimaatflop te worden”, De Morgen, 19 de junho. Consultado a 19.07.2012, em http://www.demorgen.be/dm/nl/2462/Standpunt/article/detail/1456926/2012/06/20/Rio-20-dreigt-klimaatflop-te-worden.dhtml.

Santos, B. S. (org.) (2001), Globalização. Fatalidade ou utopia? Porto: Afrontamento.

Solon, P. (2010), "Why Bolivia Stood Alone in Opposing the Cancún Climate Agreement", The Guardian, 21 de dezembro. Consultado a 20.07.2012, em http://www.guardian. co.uk/environment/cif-green/2010/dec/21/bolivia-oppose-cancun-climate-agreement.

Stern, N.; Campanale, M.; Legget, J. (orgs.) (2013), “Unburnable Carbon 2013: Wasted Capital and Stranded Assets". Carbon Tracker/The Grantham Research Institute, LSE. Consultado a 15.05.2013, em http://www.carbontracker.org/wp-content/ uploads/downloads/2013/04/Unburnable-Carbon-2-Web-Version.pdf.

Stiglitz, J. (2001), "Foreword”, in Karl Polanyi, The Great Transformation: The Political and Economic Origins of Our Time. Boston: Beacon Press, vii-xvii [2." ed.].

Stiglitz, J. (2007), Making Globalization Work. New York/London: WW Norton \& Company.

Summers, L. (1992), "Internal Memo to the World Bank", The Economist, 8 de fevereiro.

Swyngedouw, E. (2010), "Apocalypse Forever? Post-political Populism and the Spectre of Climate Change”, Theory, Culture E Society, 27(2-3), 213-232. DOI:10.1177/0263276409358728.

Trotsky, L.; Shachtman, M. (1996), The Third International After Lenin. New York: Pathfinder Press.

Wallerstein, I. (2008), “2008: The Demise of Neoliberal Globalization”, Montbly Review. Consultado a 13.07.2012, em http://mrzine.monthlyreview.org/2008/wallerstein010208.html.

Wallerstein, I. (2012), "The World Class Struggle: The Geography of Protest", IWallerstein.com, 1 de junho. Consultado a 13.07.2012, em http://www.iwallerstein. com/world-class-struggle-geography-protest/.

Welz, A. (2009), "Emotional Scenes at Copenhagen”, blog de Adam Welz, post de 8 de dezembro.

Williamson, John (2009), “A Short History of the Washington Consensus”, Law and Business Review of the Americas, 15(7).

World Bank (2012), "State and Trends in the Carbon Market 2011", maio.

Zizek,S. (2007), "Violence or Ecology: TheNew Opiate of the Masses”. Consultadoa23.03.2013, em http://www.youtube.com/watch?v=hMJdGor-sMA\&feature=youtube_gdata_player. 
